\title{
Midterm outcomes of myocardial revascularization in children
}

\author{
Nicola Viola, MD, Abdullah A. Alghamdi, MD, Osman O. Al-Radi, MD, John G. Coles, MD, \\ Glen S. Van Arsdell, MD, and Christopher A. Caldarone, MD
}

Objective: Pediatric coronary artery bypass grafting is uncommon. Small target vessels and appropriate conduit choice are the main technical challenges.

\begin{abstract}
Methods: Fourteen patients undergoing coronary artery bypass grafting from January 1986 to December 2008 were retrospectively reviewed.

Results: Median age was 10 years (range, 3-15 years); median weight was $36 \mathrm{~kg}$ (range, 12-71 kg). Indications included symptoms or evidence of inducible ischemia and angiographically documented coronary stenosis. Diagnoses included Kawasaki disease (5/14), anomalous left coronary artery originating from the pulmonary artery (2/14), previous stent implant (1/14), and metabolic disease (3/14). The remaining 3 patients had coronary stenosis after other cardiac operations. Preoperatively 5 patients $(45 \%)$ had no symptoms and $9(64 \%)$ had positive stress test. Single-vessel disease was demonstrated in $2(14 \%)$, double-vessel disease in $7(50 \%)$, triple-vessel disease in $1(7 \%)$, and left main coronary artery involvement in $4(29 \%)$. With standard cardiopulmonary bypass, $18(81 \%)$ in situ internal thoracic arteries and $4(19 \%)$ long saphenous veins were grafted. There was 1 early reoperation for graft failure. All patients survived to hospital discharge. Follow-up angiography was performed in 5 patients ( $36 \%$; median, 2 years; range, 1 day-10 years), and $1(7 \%)$ required late balloon dilatation. Median follow-up was 3.3 years ( 1 month-10 years), and 12 patients had no symptoms. There was 1 late death of noncardiac cause.
\end{abstract}

Conclusions: Pediatric coronary artery bypass grafting can be performed for a wide range of indications. Midterm results are excellent. Preoperative stress testing can detect silent myocardial ischemia. (J Thorac Cardiovasc Surg 2010;139:333-8)

Coronary artery bypass grafting (CABG) in the pediatric age group is uncommon. Kawasaki disease and anomalous origin of the coronary arteries remain the most frequent indications. In the first reported cases, an autologous saphenous vein graft (SVG) was used in the treatment of anomalous left coronary artery originating from the pulmonary artery (ALCAPA). ${ }^{1}$ In 1976, Kitamura and colleagues ${ }^{2}$ reported successful double aortocoronary bypass grafting in a 4year-old child with Kawasaki disease (mucocutaneous lymph node syndrome). ${ }^{2}$ Since the mid 1980 s, the use of the internal thoracic artery (ITA) for the treatment of Kawasaki disease and anomalous left coronary artery has been introduced and widely adopted. ${ }^{3}$ More recently, percutaneous myocardial revascularization has been adopted in the pediatric population with coronary artery disease. ${ }^{4,5}$ The latest developments in these challenging operations include other arterial conduits, such as bilateral ITAs and gastroepiploic

\footnotetext{
From The Labatt Family Heart Centre, The Hospital for Sick Children and the University of Toronto, Ontario, Canada.

Disclosures: None.

Received for publication June 19, 2007; revisions received Aug 14, 2007; accepted for publication Sept 6, 2007; available ahead of print Dec 14, 2009.

Address for reprints: Christopher A. Caldarone, The Hospital for Sick Children, 555 University Ave, Suite 1525, Toronto, ON, M5G 1X8, Ontario, Canada (E-mail: chris.caldarone@sickkids.ca).

0022-5223/\$36.00

Copyright (C) 2010 by The American Association for Thoracic Surgery doi:10.1016/j.jtcvs.2009.09.005
}

artery, and minimally invasive approaches. We report our institutional experience with CABG in pediatric patients.

\section{MATERIALS AND METHODS Population}

After institutional ethics board approval was obtained, the records of all pediatric cardiac patients who underwent CABG from January 1982 to December 2008 were evaluated. Fourteen patients were identified, and their characteristics are shown in Table 1.

The median age at the time of surgery was 10 years (range, 2.5-14.5 years). Five patients $(36 \%)$ were female. The median weight and height were $36.36 \mathrm{~kg}$ (range, $12.2-71 \mathrm{~kg}$ ) and $137.55 \mathrm{~cm}$ (range, $88-156 \mathrm{~cm}$ ), respectively.

Preoperative diagnoses included Kawasaki disease in 5 patients $(36 \%)$, Takayasu disease in $1(7 \%)$, and ALCAPA in $2(14 \%)$. Three patients $(28 \%)$ had coronary stenosis after previous surgical interventions: 1 patient had significant right coronary artery (RCA) stenosis caused by scar retraction from a previous atriotomy for closure of an atrial septal defect, 1 had severe left main coronary artery stenosis caused by compression after a Konno-type root replacement, and 1 had severe left main coronary artery stenosis develop after patch enlargement of a single coronary with ostial stenosis. One patient underwent percutaneous transluminal coronary angioplasty (PTCA) to the RCA, which resulted in acute dissection requiring surgical grafting. Of the remaining $2(14 \%), 1$ had progeria-related coronary disease and the second had familial hypercholesterolemia (Table 1).

Clinical examinations for symptoms were recorded for 12 of 14 patients. Of those, 5 had no symptoms, 3 were in Canadian Cardiovascular Society class II, and 4 were in class III. The last group reported shortness of breath and angina. Preoperative stress testing revealed reversible ischemia in 9 patients and normal results in 2 (Figure 1). In 1 child with Kawasaki disease, the preoperative rest electrocardiogram showed $\mathrm{Q}$ waves in the inferior 


\section{Abbreviations and Acronyms \\ ALCAPA $=$ anomalous left coronary artery from pulmonary artery \\ $\mathrm{CABG}=$ coronary artery bypass grafting \\ ITA $=$ internal thoracic artery \\ LAD $=$ left anterior descending coronary artery \\ PTCA = percutaneous transluminal coronary angioplasty \\ $\mathrm{RCA}=$ right coronary artery \\ SVG = saphenous vein graft}

leads, consistent with the history of an old myocardial infarction. Preoperative echocardiography was performed in all cases: 2 patients had mildly decreased left ventricular systolic function, and the remaining 12 had left ventricular ejection fraction greater than $50 \%$. The diagnostic angiograms showed single-vessel disease in 4 patients, double-vessel disease in 5, triple-vessel disease in 1, and involvement of the left main coronary artery in 4. All patients with Kawasaki disease had multiple stenoses and documented aneurysms on previous angiograms.

\section{Surgical Technique}

For surgical access, median sternotomy was used. The ITAs were harvested as pedicles in most cases. In a minority of cases, a proximal long SVG. All patients underwent mildly hypothermic or normothermic cardiopulmonary bypass and cold blood cardioplegia delivered through the aortic root. All ITAs were used as in situ grafts. Distal anastomoses were performed under a surgical microscope with interrupted sutures of 10/0 Prolene (Ethicon, Inc, Somerville, NJ) in 1 case of Kawasaki coronaropathy. In all other cases, the distal anastomoses were performed with running 8-0 Prolene sutures. Proximal anastomosis of SVGs to the ascending aorta were with a single-clamp technique with running 7-0 Prolene sutures.

\section{Statistical Methods}

A statistical software package (SAS version 9.1; SAS Institute, Inc, Cary, NC) was used for all statistical analyses. Individual patients' data were tabulated where appropriate. Categoric data were summarized as frequencies and percentages, and continuous variables were summarized as mean, medians, and SDs. Kaplan-Meier statistics were used to perform survival curves for the entire cohort. Categoric variables were compared with the $\chi^{2}$ test, and continuous variables were compared with the Student $t$ test. Analysis of variance was used to compare height, weight, and left ventricular ejection fraction before the operation and at last follow-up.

\section{RESULTS}

Median crossclamp and cardiopulmonary bypass times were 96.5 minutes (25-224 minutes), and 113 minutes (34-255 minutes), respectively. Seven patients $(50 \%)$ received 1 graft, $6(43 \%)$ received 2 grafts, and $1(7 \%)$ received 3 grafts, for a total of 22 grafts and a mean of 1.5 grafts per patient. Of those, 18 grafts $(82 \%)$ were arterial and $4(18 \%)$ were SVGs.

Five patients $(36 \%)$ underwent associated procedures. Patient 2, an 8-year-old boy, had severe familial hyperlipidemia and atherosclerosis of the aortic root and underwent unroofing and patch repair of the proximal RCA, as did patient
4, a 13-year-old girl with Takeyasu arteritis. Patient 8 required unroofing of the midportion of the left anterior descending coronary artery (LAD) and division of severe muscle bands. Patient 10, a 9-year-girl with Kabuki syndrome, underwent a complex fifth-time reoperation, during which an aortic pseudoaneurysm was repaired with the Bentall procedure and the mitral valve was repaired. Patient 13 underwent resection of the subaortic membrane (Table 2).

The median stay in the intensive care unit for the entire cohort was 43.5 hours (range, 12-192 hours), and the overall median hospital stay was 8.9 days (range, 3-24 days). After exclusion of patient 10 , who underwent a far more complex operation and was in congestive heart failure before the operation as a result of pulmonary hypertension and right ventricular failure, the median intensive care unit stay was 24 hours and the median hospital stay was 5 days.

Clinical follow-up was recorded for 13 patients, with a median interval to follow-up of 3.25 years (range, 1 month-10 years). Clinical follow-up and echocardiography were completed for 13 patients $(93 \%)$. Patient 4 , who was admitted through a charitable program for overseas patients, returned to the country of origin 2 months after the procedure and was unavailable for follow-up.

There were no perioperative deaths. There was 1 late death $(7 \%)$. Patient 1 died 2 years after the operation of noncardiac complications related to progeria.

Three patients had significant complications in the immediate postoperative period. Patient 4 had inferior wall ischemia and hemodynamic instability develop on postoperative day 1 after left ITA to LAD and diagonal artery branch 1 and patch ostioplasty of the RCA. An emergency angiogram on the same day revealed severe RCA stenosis distal to the site of the repair. The lesion was deemed not amenable to percutaneous treatment, so emergency SVG placement to the RCA was performed on the same day, with complete resolution of the ischemic changes. The subsequent postoperative course remained uneventful, and echocardiography at discharge showed mild inferior hypokinesis. Two patients $(14 \%)$ had significant postoperative arrhythmias. Patient 4 had ventricular tachycardia in association with the acute ischemic event. Patient 2 had atrial fibrillation, which resolved with antiarrhythmic medical treatment. Patient 10 had severe respiratory failure develop, necessitating reintubation and prolonged intensive care unit and hospital stays because of the underlying condition of pulmonary hypertension and reduced right ventricular function.

Five patients $(35.7 \%)$ underwent coronary angiography in the postoperative period (median interval, 3.3 years; range, 1 month-3.5 years) for clinical and echocardiography indications. Patient 1 had a diagnosis of recurrent angina made 12 months after surgery: coronary angiography showed severe stenosis at the site of the distal anastomosis of SVG to the circumflex artery. PTCA was performed with immediate clinical improvement. A second routine 
TABLE 1. Characteristics of pediatric patients undergoing coronary artery bypass grafting from January 1982 to December 2008

\begin{tabular}{|c|c|c|c|c|c|c|}
\hline Case & Age (y) & Weight $(\mathrm{kg})$ & Diagnosis & CCS & Electrocardiography & Angiography ( $\%$ stenosis) \\
\hline 1 & 10 & 14 & Progeria & III & ST changes & LAD $100 \%$, Cx $80 \%$ \\
\hline 2 & 8 & 38 & Familial hypercholesterolemia & 0 & ST changes & $\begin{array}{c}\text { LMCA } 80 \% \text {, LAD } 80 \%, \text { Cx } \\
80 \% \text {, RCA } 90 \%\end{array}$ \\
\hline 3 & 9 & 20.5 & $\begin{array}{c}\text { ALCAPA, sp ligation of } \\
\text { ALCAPA }\end{array}$ & - & - & LMCA $100 \%$ \\
\hline 4 & 13 & 38.8 & Takayasu disease & III & $\begin{array}{l}\text { ST changes } \\
\text { anterolateral, inferior }\end{array}$ & LMCA $100 \%$, RCA $80 \%$ \\
\hline 5 & 14 & 41.5 & Wilms tumor & - & - & RCA $100 \%$ \\
\hline 6 & 13 & 37 & $\begin{array}{c}\text { ALCAPA, sp reimplantation } \\
\text { of LMCA } 1987\end{array}$ & II-III & $\begin{array}{c}\text { ST changes } \\
\text { anterolateral, inferior }\end{array}$ & LMCA $100 \%$ \\
\hline 7 & 13 & 43.8 & $\begin{array}{c}\text { Kawasaki, LAD stent } 1996, \\
\text { LAD PTCA } 1999\end{array}$ & II & Normal & $\begin{array}{c}\text { LAD (aneurysm) and stent } \\
90 \%\end{array}$ \\
\hline 8 & 14 & 71 & Hypertrophic cardiomyopathy & 0 & $\begin{array}{c}\text { ST changes } \\
\text { basal septum, inferolateral }\end{array}$ & $\begin{array}{c}\text { LAD } 80 \% \text {, RCA } 80 \%, \\
\text { intimal flap }\end{array}$ \\
\hline 9 & 9 & 65 & Kawasaki, LAD stent $\times 2$ & 0 & Normal & $\begin{array}{c}\text { LAD (aneurysm) and stent } \\
90 \%, \text { RCA } 100 \%\end{array}$ \\
\hline 10 & 9 & 22.4 & $\begin{array}{l}\text { Kabuki syndrome, } \\
\text { sp coarctation repair, } \\
\text { sp subaortic membrane } \\
\text { resection, sp Konno } \\
\text { and AVR }\end{array}$ & III & ST changes $\mathrm{V}_{3}-\mathrm{V}_{6}$ & RCA $100 \%$ \\
\hline 11 & 3 & 12.2 & Kawasaki & 0 & $\begin{array}{l}\text { ST changes } \\
\text { anterior, inferior }\end{array}$ & $\begin{array}{c}\text { LAD (aneurysms) and stent } \\
100 \%, \text { RCA (aneurysms) } \\
100 \%\end{array}$ \\
\hline 12 & 10 & 38 & Kawasaki & III & $\begin{array}{c}\text { ST changes } \\
\text { inferior, sinus bradycardia }\end{array}$ & $\begin{array}{c}\text { LAD (aneurysm) } 100 \% \text {, RCA } \\
100 \%\end{array}$ \\
\hline 13 & 12 & 41 & Postsurgical LMCA stenosis & II & - & 1 right, left, Cx; LMCA 100\% \\
\hline 14 & 9 & 25.9 & Kawasaki & 0 & ST changes inferior & $\begin{array}{c}\text { LAD (aneurysm) } 100 \%, \text { RCA } \\
100 \% \\
\end{array}$ \\
\hline
\end{tabular}

$C C S$, Canadian Cardiovascular Society classification of angina; $L A D$, left anterior descending coronary artery; $C x$, circumflex artery; $L M C A$, left main coronary artery; $R C A$, right coronary artery; $A L C A P A$, anomalous left coronary artery originating from the pulmonary artery; $s p$, status post; PTCA, percutaneous transluminal coronary angioplasty; $A V R$, aortic valve replacement.

angiogram performed 3 years after the operation showed a new stenosis at the origin of the left ITA, although this was not associated with ischemia and no further intervention was undertaken. Three patients underwent angiography because of nonspecific changes on routine electrocardiography or nonspecific symptoms: all grafts were patent, and no significant stenoses were found. Moreover, results of stress testing were negative in 2 these 3 patients. One patient underwent early coronary angiography on postoperative day 6 , before discharge, and both ITA grafts were seen to be patent and free of stenosis.

Of the 13 survivors, 12 were free of symptoms $(86 \%)$ and without notable neurocognitive impairment. Patient 10 , who had a difficult postoperative course because of the preexisting condition of Kabuki syndrome, poor right ventricular function, and pulmonary hypertension, was in severe cardiac failure but without signs of active ischemia according to stress testing and echocardiography. This patient was not referred for transplant because of significant comorbidities, including irreversible pulmonary hypertension and kidney failure. At the time of last follow-up, the patient was still alive and receiving home-based palliative care.
Echocardiography at follow-up showed good biventricular ventricular function in 11 patients $(78.5 \%)$, moderate left ventricular systolic function in $2(14.3 \%)$, and severely reduced right ventricular function in $1(7 \%)$. Overall, the left ventricular ejection fraction remained preserved $(P=.45$; Figure 2). The body mass index increased significantly between measurements immediately before surgery and at last follow-up.

Nine patients $(64 \%)$ received long-term medical therapy. This consisted of warfarin sodium (INN warfarin) in 5 cases $(35.7 \%)$, antiplatelet therapy in $5(35.7 \%)$, and atorvastatin calcium (Lipitor, INN atorvastatin) in 2 $(14 \%)$.

\section{DISCUSSION}

In the pediatric population, coronary artery stenosis and the resulting myocardial ischemia are associated with significant morbidity and mortality including myocardial infarction, cardiac failure, and sudden death. ${ }^{1,6,7} \mathrm{CABG}$ is the most commonly reported mode of myocardial revascularization in children with Kawasaki disease, the first cases of which were reported in the mid 1970s. ${ }^{2,8}$ 
Pre-Operative Symptoms

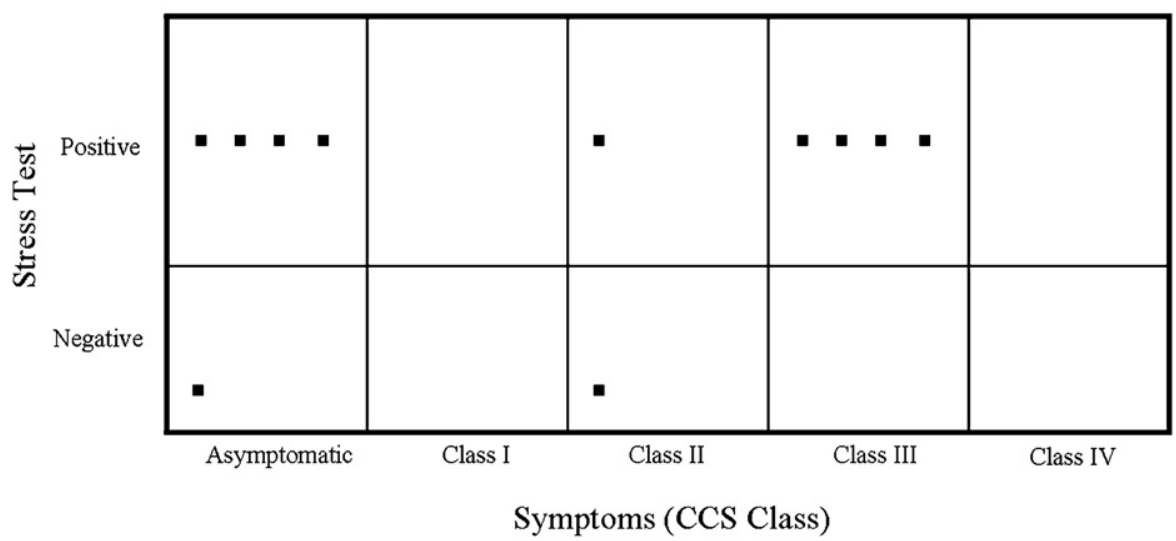

FIGURE 1. Relationship between symptoms and stress testing in preoperative evaluation. Note only 1 symptom-free patient had negative stress test, whereas almost all symptom-free patients showed signs of inducible ischemia on stress testing. Dots represent single patients. CCS, Canadian Cardiovascular Society classification of angina.

In patients with Kawasaki disease, the presence of giant aneurysms and multiple stenoses poses a high risk of myocardial infarction and death. ${ }^{9}$ In the late 1980s the Research Committee on Kawasaki Disease proposed severe left main stem stenosis, proximal LAD stenosis, and triple-vessel disease without significant collateral circulation as the main in- dications for surgery. ${ }^{10}$ Suzuki and colleagues ${ }^{11}$ reviewed the cases of more than 300 patients with Kawasaki disease and proposed a protocol of indications according to coronary lesions (disease involving the left main, disease involving the proximal LAD, multivessel disease) and the presence of inducible ischemia. More recently, Mavroudis and associates ${ }^{12}$

TABLE 2. Procedures and results of pediatric patients undergoing coronary artery bypass grafting from January 1982 to December 2008

\begin{tabular}{|c|c|c|c|c|c|c|c|c|c|}
\hline Case & Procedures & $\begin{array}{l}\text { Associated } \\
\text { procedures }\end{array}$ & $\begin{array}{r}\text { CPB } \\
(\mathrm{min}) \\
\end{array}$ & $\begin{array}{c}\mathrm{XC} \\
(\mathrm{min}) \\
\end{array}$ & $\begin{array}{l}\text { Perioperative } \\
\text { complications }\end{array}$ & $\begin{array}{c}\text { Hospital } \\
\text { stay (d) }\end{array}$ & Patency & $\begin{array}{c}\text { Follow-up } \\
(y)\end{array}$ & Outcome \\
\hline 1 & LITA-LAD, SVG-Cx & & 90 & - & & 15 & PTCA, SVG-Cx & 12 & Death \\
\hline 2 & $\begin{array}{l}\text { LITA-LAD, SVGs- } \\
\text { RCA, D1 }\end{array}$ & RCA plasty & 157 & 128 & Arrhythmia & 3 & $\begin{array}{l}\text { Patent grafts, patent } \\
\text { RCA }\end{array}$ & 10 & Asymptomatic \\
\hline 3 & LITA-LAD & & 107 & 57 & & 6 & & 10 & Asymptomatic \\
\hline 4 & LITA-LAD, SVG-D1 & RCA plasty & 113 & 95 & $\begin{array}{l}\text { Arrhythmia, } \\
\text { emergency } \\
\text { SVG-RCA }\end{array}$ & 23 & & 4 & Asymptomatic \\
\hline 5 & RITA-RCA & & - & - & & 5 & & 6 & Asymptomatic \\
\hline 6 & LITA-LAD, RITA-Cx & & 234 & 122 & & 5 & & 3.3 & Asymptomatic \\
\hline 7 & LITA-LAD & & 34 & 25 & & 3 & & 4.4 & Asymptomatic \\
\hline 8 & RITA-RCA & Unroofing of LAD & 64 & 55 & & 5 & & 3.3 & Asymptomatic \\
\hline 9 & $\begin{array}{l}\text { LITA-LAD, RITA- } \\
\text { RCA }\end{array}$ & & 84 & 65 & & 9 & Patent grafts & 3.4 & Asymptomatic \\
\hline 10 & RITA-RCA & MVR, ARR & 255 & 224 & $\begin{array}{l}\text { Respiratory } \\
\text { failure, } \\
\text { reintubation }\end{array}$ & 24 & Patent grafts & 3.2 & NYHA III \\
\hline 11 & $\begin{array}{l}\text { LITA-LAD, RITA- } \\
\text { RCA }\end{array}$ & & 221 & 191 & & 9 & Patent grafts & 1.4 & Asymptomatic \\
\hline 12 & $\begin{array}{l}\text { LITA-LAD, RITA- } \\
\text { PDA, SVGs-PL, } \\
\text { D1 }\end{array}$ & & 123 & 113 & & 5 & & 0.1 & Asymptomatic \\
\hline 13 & LITA-LAD & $\begin{array}{c}\text { Subaortic membrane } \\
\text { resection }\end{array}$ & 119 & 98 & & 9 & & 0.1 & Asymptomatic \\
\hline 14 & $\begin{array}{l}\text { LITA-LAD, RITA- } \\
\text { RCA }\end{array}$ & & 59 & 52 & & 4 & & 0.1 & Asymptomatic \\
\hline
\end{tabular}

$\overline{C P B}$, Cardiopulmonary bypass; $X C$, crossclamp; $L I T A$, left internal thoracic artery; $L A D$, left anterior descending coronary artery; $S V G$, saphenous vein graft; $C x$, circumflex artery; $P T C A$, percutaneous transluminal angioplasty; $R C A$, right coronary artery; $D 1$, diagonal branch $1 ; R I T A$, right internal thoracic artery; $M V R$, mitral valve repair; $A R R$, aortic root replacement; NYHA, New York Heart Association; PDA, posterior descending artery; $P L$, posterolateral artery. 


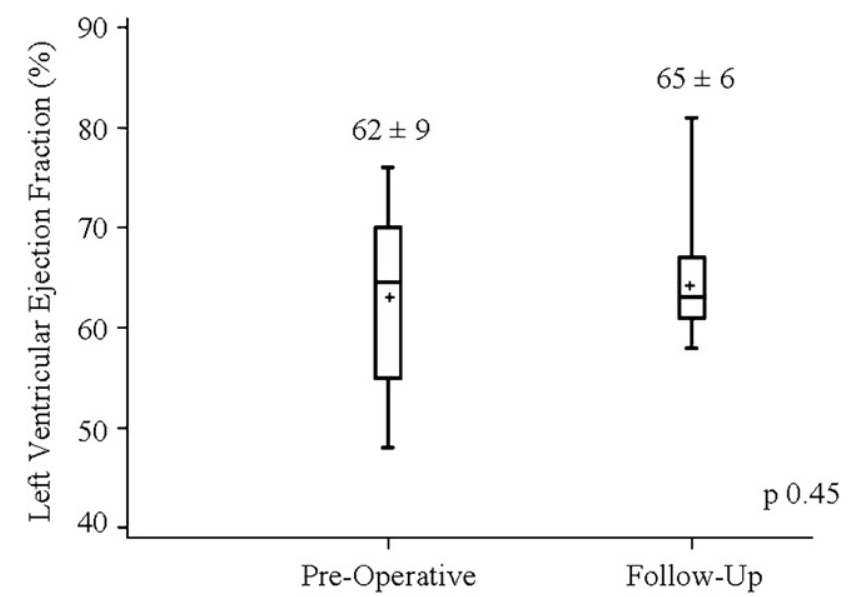

FIGURE 2. Left ventricular ejection fraction was preserved both before operation and at follow-up $(P=.45)$.

have proposed operating on children with both symptoms and documented stenoses greater than $50 \%$ and giant aneurysms or on patients without symptoms but with documented inducible ischemia or demonstrated angiographic progression of the stenosis degree. The recognized progressive nature of the coronary disease provides support for this approach. ${ }^{13,14}$

CABG has also been used for the treatment of ALCAPA, although less frequently. The first cases were performed in the early $1960 \mathrm{~s},{ }^{1,3}$ before the introduction of the direct reimplantation of the left main coronary artery into the aorta by Neches and colleagues. ${ }^{15}$ During the last 4 decades, coronary origin anomalies have been treated successfully with a wide array of techniques, such as reimplantation, repair techniques, and CABG. ${ }^{6,7,16}$ During the last 2 decades, the indications for CABG have expanded from Kawasaki disease and congenital anomalies to problems resulting from previous surgical procedures, such as correction of transposition of great arteries, or from failed percutaneous interventions.

The underlying conditions leading to coronary stenosis in our study were heterogeneous, and the indications for intervention were broad. Clinical indications included angina or anginalike symptoms and the documentation of inducible ischemia on stress testing. In all cases, coronary stenoses exceeded $70 \%$ of diameter on angiography. Giant aneurysms and multivessel involvement were documented preoperatively in all patients with Kawasaki disease. In 2 cases, we operated to treat single-vessel disease not involving the left main stem or the proximal LAD. Both patients had severe stenosis of the RCA in the setting of postoperative complications from other cardiac interventions. In 1 case the lesion was considered not amenable to percutaneous intervention. In the other case, CABG was performed in conjunction with reoperative root replacement and mitral valve repair, which were the primary indications for surgery.

Interestingly, 5 of 6 symptom-free patients had positive stress test results, the same prevalence as among the 6 patients with symptoms. This finding supports the notion that coronary disease may often be present in symptom-free pediatric patients with such high-risk conditions as Kawasaki disease and other forms of vasculitis or after repair of congenital coronary anomalies or metabolic conditions such as hyperlipidemia. A high index of suspicion for coronary obstruction should be maintained in such cases.

Emergency CABG performed to correct acute ischemia after PTCA has been reported. ${ }^{12}$ One patient in our series required emergency CABG after a failed attempt at PTCA that resulted in coronary artery dissection and acute ischemia. The operation reversed the hemodynamic compromise changes with complete regression of the ischemic damage, as documented by follow-up echocardiography.

In 3 cases, we performed coronary bypass in the setting of stent stenosis. In 2 cases, the revascularization was performed early after the diagnosis, with excellent results. This seems to support the notion that the early rescue of hibernating myocardium seems to enhance the postoperative myocardial recovery significantly. ${ }^{17,18}$

Despite the technical challenges posed by the small dimensions of vascular access and coronary system, percutaneous interventions have been performed successfully in this population. ${ }^{3-5}$ In our series, both stents were nondrug-eluting stents. Recently, Salloum and coworkers ${ }^{5}$ reported implanting a drug-eluting stent in a 5-year-old girl, with satisfactory immediate results. The impact of this kind of stent on long-term patency remains unknown.

Grafts with autologous SVGs are associated with early restenosis. ${ }^{11,19,20}$ To improve long-term patency, ITA grafts were introduced in the late 1980s, and during the last 2 decades, such other arterial conduits as the gastroepiploic artery have been used successfully. ${ }^{3,8,11,21}$ Arterial grafts are associated with better patency rates than SVGs, and, importantly in the pediatric population, arterial grafts have been demonstrated to grow with the rest of the body. ${ }^{22,23}$ Furthermore, the patency rate of ITAs in the long term does not seem to be influenced by the diameter of the native vessel at the time of implantation. ${ }^{19}$

Since the early 1990s, bilateral ITAs have been successfully used in pediatric myocardial revascularization. ${ }^{13}$ In a large multicenter study involving 162 patients who underwent CABG for Kawasaki disease, Kitamura and associates $^{24}$ found that ITA patency rate was $77 \%$ at 85 months, versus a disappointing $46 \%$ for venous grafts. The superiority of arterial grafts was also seen when ITAs were anastomosed to non-LAD territories. There was a tendency for a slightly worse performance of the gastroepiploic artery relative to the ITAs, although it still scored better than the SVGs. Kitamura and associates ${ }^{24}$ also showed that vein patency was particularly poor in small children, with a patency rate of less than $30 \%$ in children younger than 7 years.

Graft failure has been reported for patients with Kawasaki disease undergoing CABG in the presence of giant aneurysms. This has been attributed to the recanalization of the 
native vessel as a result of the healing process of the vasculitic lesions. ${ }^{12}$ In our series, patients with Kawasaki disease had aneurysms on angiography at the time of surgery, which was indicated by symptoms and positive stress testing. At follow-up, these patients had no symptoms, and 2 of them underwent control angiography that showed patent grafts and good runoff.

In our institution, we have been using single or bilateral ITAs in all our patients. In the few cases in which SVGs were used, they were grafted to the RCA and circumflex artery territory. The only demonstrated graft failure at 1 year was that of SVG to the circumflex artery.

In 1 case of Kawasaki disease, we used the surgical microscope to perform bilateral ITA grafting to the LAD and RCA, which measured $1 \mathrm{~mm}$ in diameter according to operative report. The patient underwent angiography on discharge from the hospital, and both grafts were patent with excellent runoff. Three more patients underwent angiography 3.3 years (mean) after the procedure: in all 3, both arterial and venous grafts were patent with good runoff. The fate of these grafts on the long term is not known, but at followup no patients had recurrent symptoms of angina. Moreover, stress testing confirmed the absence of inducible ischemia.

\section{Study Limitations}

This study presents a single-institution experience with a small cohort of patients. Data were retrospectively collected and analyzed. The population investigated was heterogeneous in terms of diagnosis, indications, and surgical treatment. Although the clinical and echocardiographic data were $93 \%$ complete at the time of follow-up, only 5 patients underwent follow-up angiography. Even though the surgical treatment of these patients remained consistent during the last 2 decades, with extensive use of arterial revascularization and single-clamp technique, changes in the medical treatment occurred. This may have had an impact on the overall prognosis in the long term, but these data are still being evaluated.

\section{CONCLUSIONS}

We have shown that CABG can be performed in the pediatric population for a wide range of indications with excellent short-term and midterm results. Preoperative stress testing is useful in detecting silent myocardial ischemia. In high-risk populations, the absence of symptoms does not rule out significant coronary disease. Generally, pediatric myocardial revascularization is associated with satisfactory graft patency, absence of ischemic symptoms, preservation of ventricular function, and appropriate body growth.

\section{References}

1. Cooley DA, Hallman GL, Bloodwell RD. Definitive surgical treatment of anomalous origin of the left coronary artery from the pulmonary artery: indications and results. J Thorac Cardiovasc Surg. 1966;52:798-808.
2. Kitamura S, Kawashima Y, Fujita T, Mori T, Oyama C. Aortocoronary bypass grafting in a child with coronary artery obstruction due to mucocutaneous lymphnode syndrome: report of a case. Circulation. 1976;53:1035-40.

3. Fortune RL, Baron PJ, Fitzgerald JW. Atresia of the left main coronary artery: repair with left internal mammary artery bypass. J Thorac Cardiovasc Surg. 1987; 94:150-1.

4. Kawata T, Hasegawa J, Yoshida Y, Yoshikawa Y, Kawachi K, Kitamura S. Percutaneous transluminal coronary angioplasty of the left internal thoracic artery graft: a case report in a child. Cathet Cardiovasc Diagn. 1994;32: 340-2.

5. Salloum JG, Dodd DA, Slosky D, Zhao DX. Treatment of unprotected left main coronary artery stenosis in a 5-year-old heart transplant patient using a sirolimuseluting stent. J Heart Lung Transplant. 2007;26:1061-4.

6. Arciniegas E, Farooki ZQ, Hakimi M, Green EW. Management of anomalous left coronary artery from the pulmonary artery. Circulation. 1980;62:I180-9.

7. Vouhé PR, Baillot-Vernant F, Trinquet F, Sidi D, de Geeter B, Khoury W, et al. Anomalous left coronary artery from the pulmonary artery in infants. Which operation? When? J Thorac Cardiovasc Surg. 1987;94:192-9.

8. Ino T, Iwahara M, Boku H, Akimoto K, Shimura N, Nishimoto K, et al. Aortocoronary bypass surgery for Kawasaki disease. Pediatr Cardiol. 1987;8:195-7.

9. Kato H, Sugimura T, Akagi T, Sato N, Hashino K, Maeno Y, et al. Long-term consequences of Kawasaki disease: a 10- to 21-year follow-up study of 594 patients. Circulation. 1996;94:1379-85.

10. Guidelines for treatment and management of cardiovascular sequelae in Kawasaki disease. Subcommittee of Cardiovascular Sequelae, Subcommittee of Surgical Treatment, Kawasaki Disease Research Committee. Heart Vessels. 1987; 3:50-4.

11. Suzuki A, Kamiya T, Ono Y, Okuno M, Yagihara T. Aortocoronary bypass surgery for coronary arterial lesions resulting from Kawasaki disease. J Pediatr. 1990;116:567-73.

12. Mavroudis C, Backer CL, Duffy CE, Pahl E, Wax DF. Pediatric coronary artery bypass for Kawasaki congenital, post arterial switch, and iatrogenic lesions. Ann Thorac Surg. 1999;68:506-12.

13. Kitamura S, Kawachi K, Seki T, Morita R, Nishii T, Mizuguchi K, et al. Bilateral internal mammary artery grafts for coronary artery bypass operations in children. J Thorac Cardiovasc Surg. 1990;99:708-15.

14. Kitamura $S$. The role of coronary bypass operation on children with Kawasaki disease. Coron Artery Dis. 2002;13:437-47. Erratum in: Coron Artery Dis. 2003;14: 95.

15. Neches WH, Mathews RA, Park SC, Lenox CC, Zuberbuhler JR, Siewers RD, et al. Anomalous origin of the left coronary artery from the pulmonary artery: a new method of surgical repair. Circulation. 1974;50:582-7.

16. Suma K, Takeuchi Y, Shiroma K, Tsuji T, Inoue K, Yoshikawa T, et al. Cardiac surgery of eight children with Kawasaki disease. Jpn Heart J. 1981;22: 605-16.

17. Greene MA, Gray LA Jr, Slater AD, Ganzel BL, Mavroudis C. Emergency aortocoronary bypass after failed angioplasty. Ann Thorac Surg. 1991;51:194-9.

18. Kozman H, Cook JR, Wiseman AH, Dann RH, Engelman RM. Presence of angiographic coronary collaterals predicts myocardial recovery after coronary bypass surgery in patients with severe left ventricular dysfunction. Circulation. 1998; 98(19 Suppl):II57-61.

19. Inoue T, Otaki M, Oku H, Fukuda T, Shinohara T. Follow-up study of coronary artery bypass grafting in patients with Kawasaki disease. Am Heart J. 2001;142: $740-4$.

20. Kitamura S, Kawachi K, Harima R, Sakakibara T, Hirose H, Kawashima Y. Surgery for coronary heart disease due to mucocutaneous limphnode syndrome (Kawasaki disease): report of 6 patients. Am J Cardiol. 1983;51:444-8.

21. Brackenbury E, Gardiner H, Chan K, Hickey M. Internal mammary artery to coronary artery bypass in paediatric cardiac surgery. Eur J Cardiothorac Surg. 1998; 14:639-42.

22. Kitamura S, Seki T, Kawaki K. Excellent patency and growth potential of internal mammary artery grafts in pediatric coronary artery bypass surgery: new evidence for a "live" conduit. Circulation. 1988;78:129-39.

23. Kameda Y, Kitamura S, Taniguchi S, Kawata T, Mizuguchi K, Nishioka H, et al. Differences in adaptation to growth of children between internal thoracic artery and saphenous vein coronary bypass grafts. J Cardiovasc Surg (Torino). 2001; 42:9-16.

24. Kitamura S, Kameda Y, Seki T, Kawachi K, Endo M, Takeuki Y, et al. Long-term outcome of myocardial revascularization in patients with Kawasaki coronary artery disease. A multicenter cooperative study. I Thorac Cardiovasc Surg. 1994; 107(3):663-74. 